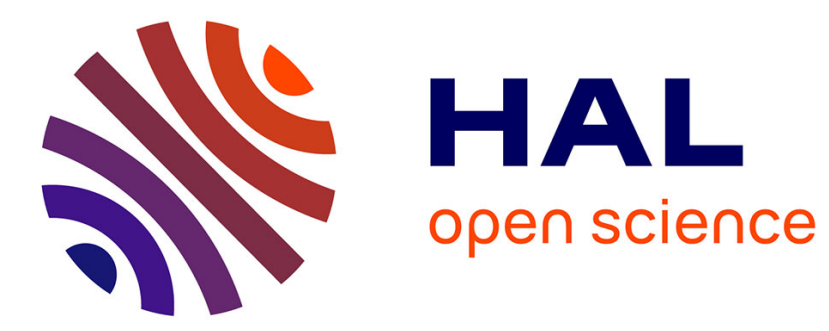

\title{
Laboratory alluvial fans in one dimension
}

\author{
L. Guerit, F. Métivier, O. Devauchelle, E. Lajeunesse, L. Barrier
}

\section{To cite this version:}

L. Guerit, F. Métivier, O. Devauchelle, E. Lajeunesse, L. Barrier. Laboratory alluvial fans in one dimension. Physical Review E: Statistical, Nonlinear, and Soft Matter Physics, 2014, 90, pp.022203. 10.1103/PhysRevE.90.022203 . hal-01499810

\section{HAL Id: hal-01499810 https://hal.science/hal-01499810}

Submitted on 13 Apr 2017

HAL is a multi-disciplinary open access archive for the deposit and dissemination of scientific research documents, whether they are published or not. The documents may come from teaching and research institutions in France or abroad, or from public or private research centers.
L'archive ouverte pluridisciplinaire HAL, est destinée au dépôt et à la diffusion de documents scientifiques de niveau recherche, publiés ou non, émanant des établissements d'enseignement et de recherche français ou étrangers, des laboratoires publics ou privés. 


\title{
Laboratory alluvial fans in one dimension
}

\author{
L. Guerit, F. Métivier, ${ }^{*}$ O. Devauchelle, E. Lajeunesse, and L. Barrier \\ Institut de Physique du Globe de Paris - Sorbonne Paris Cité, Université Paris Diderot, \\ CNRS, UMR7154, 1 rue Jussieu, 75238 Paris Cedex 05, France
}

(Dated: July 21, 2014)

\begin{abstract}
When they reach a flat plain, rivers often deposit their sediment load into a cone-shaped structure called alluvial fan. We present a simplified experimental set-up which reproduces, in one dimension, basic features of alluvial fans. A mixture of water and glycerol transports and deposits glass beads between two transparent panels separated by a narrow gap. As the beads, which mimic natural sediments, get deposited in this gap, they form an almost one-dimensional fan. At a moderate sediment discharge, the fan grows quasi-statically and maintains its slope just above the threshold for sediment transport. The water discharge determines this critical slope. At leading order, the sediment discharge only controls the velocity at which the fan grows. A more detailed analysis reveals a slight curvature of the fan profile, which relates directly to the rate at which sediments are transported.
\end{abstract}

\section{INTRODUCTION}
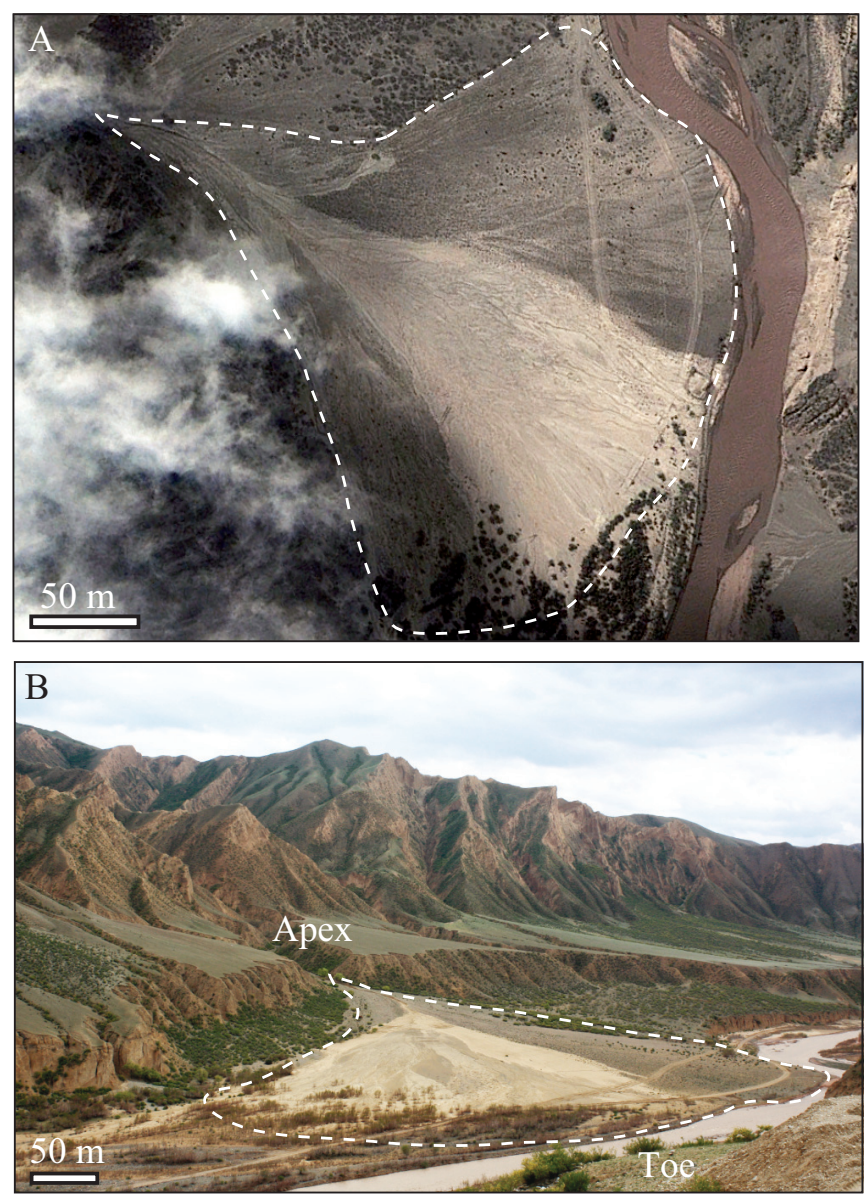

Figure 1. (Color online) A) DigitalGlobe satellite view (from Google Earth) and B) field photograph of an alluvial fan in the Tian Shan Mountains, China. The sediment cone is highlighted with a white dotted line. Light colors indicate freshly deposited sediments.

\footnotetext{
* Corresponding author: metivier@ipgp.fr
}

As they leave mountain ranges, rivers are loaded with eroded materials in the form of sediment grains. When they reach a flatter area, they tend to deposit the coarser part of their load. If the deposition area is unconfined, the sediments build up a cone-shaped structure called an alluvial fan. Typically, the fan is roughly symmetric about its apex (its highest point from which the river flows) (figure 1) [1-3] .

To build an alluvial fan, a river needs (i) to transport sediments and (ii) to deposit them evenly across the fan surface. Most of the time, the river continuously deposits sediments along its path. With time, this process elevates the river's bed until its path becomes unstable. At this point, the river overflows its banks and finds a lower path on the fan surface. This catastrophic event is called an avulsion. The new channel, in turn, will slowly fill itself up with sediments, until the next avulsion. As a signature of past avulsions, abandoned channels furrow the fan surface (figure 1). This process, which explains how an alluvial fan roughly maintains radial symmetry as it grows, has already been successfully reproduced in the lab [4-7].

Most alluvial fans exhibit a relatively constant slope between the apex and the toe [8-10], but the physical origin of this feature remains unclear and somewhat paradoxical. Indeed, the slope of a river, and thus that of the fan it builds, depends chiefly on its water discharge and sediment load $[8,12]$. Since the river deposits a significant part of its sediment load on the fan surface while the water discharge remains roughly constant, one would expect the fan slope to reflect the downstream decrease of the sediment load [11].

Observations from one-dimensional laboratory experiments show a roughly linear profile with a slight curvature [13]. Recent two-dimensional experiments generate fans with a constant slope, which does not depend significantly on the sediment discharge [7]. These morphological characteristics remain to be explained.

Inspired by previous experiments, we suggest that the nearly uniform slope of an alluvial fan results from the river being near the threshold for sediment transport [7]. 


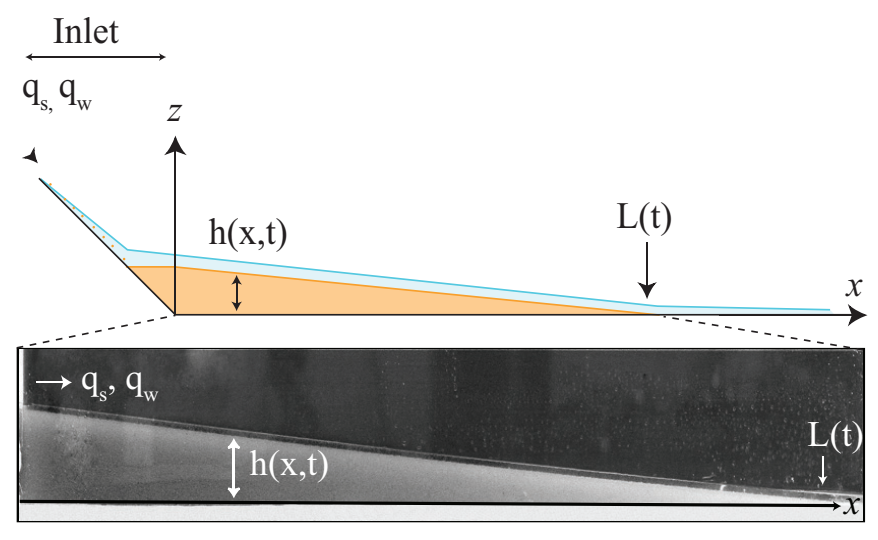

Figure 2. (Color online) A) Experimental set-up and definitions. Fluid and sediment flows from left to right. B) Side photograph of an experimental fan (vertical exaggeration $\times 2$ ).

Indeed, for the shear stress induced by the stream on its bed to match exactly the strength necessary to move sediment particles, the river must adjust its slope to a specific value [14-18]. Therefore, if the growth of an alluvial fan is driven by a moderate sediment flux, we should observe a quasi-static regime, with the fan geometry being virtually that of equilibrium.

This view would reunite alluvial fans with sand heaps in the class of granular structures which grow near a critical angle [7, 19]. Contrary to sand heaps however, the angle of an alluvial fan would depend on the system parameters, and notably on the grain size.

To investigate the quasi-static growth of an alluvial fan, we have developed a simple laboratory experiment which produces alluvial fans confined between two plates (section II). This one-dimensional experiment is designed to facilitate our physical understanding, as opposed to more realistic models [20]. At the cost of (i) precluding avulsions, (ii) forcing the width of the channel, and (iii) remaining near threshold, this one-dimensional configuration allows for direct comparison between theory and experiments (sections II and III).

\section{LABORATORY FAN NEAR THRESHOLD}

\section{A. Experimental set-up}

Our one-dimensional fan is confined between two $1 \mathrm{~m}$ long Plexiglas panels separated by a $2.5 \mathrm{~cm}$-wide gap (figure 2). A mixture of water and glycerol (80\% glycerol in volume, density $\rho_{f}=1210 \mathrm{~kg} \mathrm{~m}^{-3}$ ) is introduced from the left-hand side of the set-up at constant rate and leaves freely the channel at the outlet. Its high viscosity $(\mu=40-60 \mathrm{mPas})$ ensures that the flow remains laminar (the Reynolds number is of order 10). To generate a fan, this fluid is loaded with glass beads (diameter $D=477 \mu \mathrm{m}$, density $\rho_{s}=2485 \mathrm{~kg} \mathrm{~m}^{-3}$ ). The

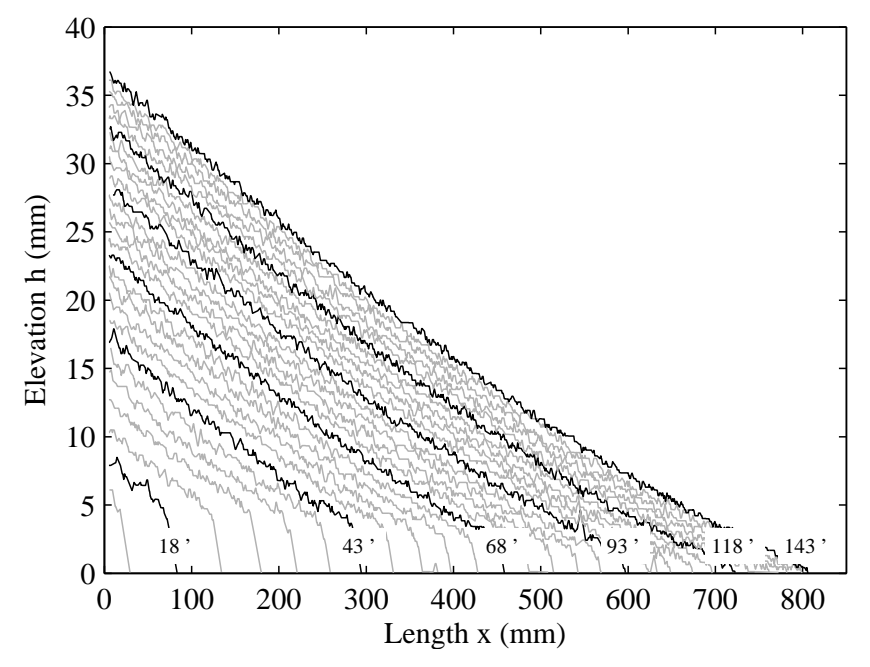

Figure 3. Digitized fan profiles at successive times during a single experimental run (sediment discharge $Q_{s}=$ $4.6 \mathrm{~g} \mathrm{~min}^{-1}$, water discharge $\left.Q_{w}=0.60 \mathrm{~L} \mathrm{~min}^{-1}\right)$. Time starts at the beginning of the experiment. Black and grey profiles are separated by $5 \mathrm{~min}$.

sediment discharge is controlled by the rotation of an Archimede's screw. In this study, we only vary the water and sediment discharges $\left(Q_{w}=0.5-1.3 \mathrm{~L} \mathrm{~min}^{-1}\right.$ and $\left.Q_{s}=0.8-3.6 \mathrm{~cm}^{3} \mathrm{~min}^{-1}\right)$, while we keep the other parameters constant.

When the experiment starts, glass beads get deposited near the inlet. After a transient lasting a few minutes, the deposited sediments form a tapering structure, which becomes larger as more glass beads settle on its surface (figure 2). This one-dimensional fan grows continuously until it eventually reaches the outlet.

Every minute, we record a picture of the fan, from which the elevation profile $h$ is digitized (figure 3 ). The fan maintains a quasi-triangular shape during its growth, and its slope does not vary significantly (figure 3 ), thus suggesting a self-affine process, in accordance with previous experimental findings [13].

\section{B. Fan near threshold}

To formalize the notion of a fan growing near threshold, we first need to establish the transport law for our sediments. We use a separate set-up, developed previously [21]. A $3.2 \mathrm{~cm}$-wide channel is filled with the same glass beads our fans are built of and submitted to constant inputs of fluid and sediments. After about one day, the system has reached steady state and we measure the flow-induced shear stress on the bed. This procedure contrasts with that of most previous authors, who imposed the shear stress and measured the resulting sediment discharge [22].

In an open channel of width $W$, the shear stress $\tau$ 


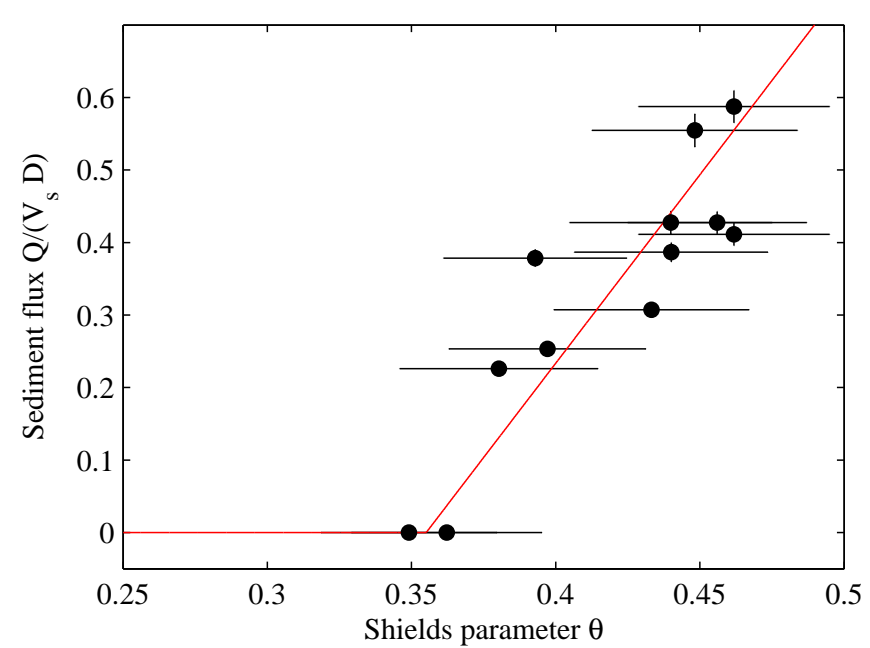

Figure 4. (Color online) Transport law of the sediments (477$\mu \mathrm{m}$ glass beads in glycerol mixed with $20 \%$ of water) used to build our experimental fans. Black dots: measurements, red (gray) line: equation (3) fitted to the data.

exerted by a viscous flow on the bed reads:

$$
\tau=\left(\rho_{f} g S\right)^{2 / 3}\left(\frac{3 Q_{w} \mu}{W}\right)^{1 / 3}
$$

where $S$ and $g$ are the bed slope and the acceleration of gravity, respectively. According to the Coulomb criterion for a granular material, the particles are entrained by the flow only if the ratio of the shear stress to the particle weight exceeds the critical friction coefficient. This threshold can be expressed in terms of the Shields parameter $\theta$ defined as:

$$
\theta=\frac{\tau}{\left(\rho_{s}-\rho_{f}\right) g D} .
$$

Typically, sediment transport vanishes below the threshold Shields parameter $\theta_{c}$ corresponding to the critical friction coefficient and increases with the Shields parameter beyond that point. At leading order, this increase is usually proportional to the distance to the threshold $\theta-\theta_{c}$ and our glass beads are no exception (figure 4) [21, 22].

Fitting a first-order transport law to our calibration data, we find:

$$
q_{s}=\alpha V_{s} D\left(\theta-\theta_{c}\right)
$$

where the proportionality coefficient is $\alpha \approx 4.9 \pm 0.3$, and the threshold Shields parameter is $\theta_{c} \approx 0.35 \pm 0.04$, in accordance with previous findings in viscous flows [21, 23]. Stokes's settling velocity is defined as $V_{s}=\left(\rho_{s}-\right.$ $\left.\rho_{f}\right) g D^{2} /(18 \mu)$.

Based on this transport law, we now investigate how the threshold for sediment transport could set the geometry of an experimental fan. To grow, the fan must be the

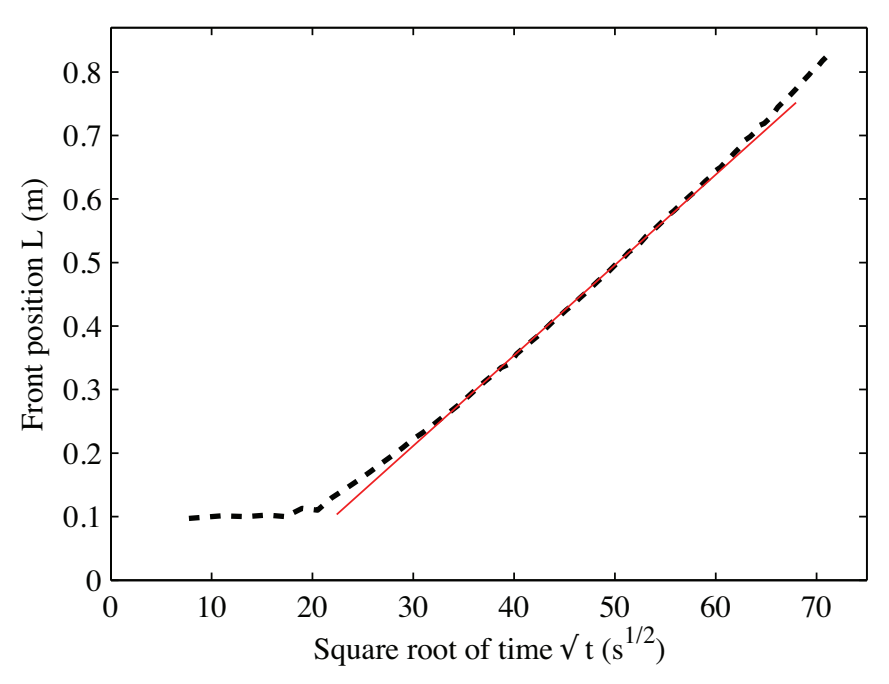

Figure 5. (Color online) The black dotted line correspond to the evolution of the length $L$ of an experimental fan $\left(Q_{s}=7.0 \mathrm{~g} \mathrm{~min}^{-1}, Q_{w}=0.82 \mathrm{~L} \mathrm{~min}^{-1}\right)$. The red (gray) line corresponds to equation (5) with a time shift of $15 \mathrm{~min}$.

place of sediment transport. However, if we maintain a low sediment discharge $Q_{s}$, the Shields parameter should remain close to its threshold value $\theta_{c}$. More specifically, after equation (3), if $Q_{s}$ is much smaller than $V_{s} D W$, then the Shields parameter tends towards $\theta_{c}$. Together with equations (1) and (2), this approximation translates into a critical slope $S_{c}$ defined as:

$$
S_{c}=\frac{\left(\rho_{s}-\rho_{f}\right)}{\rho_{f}} \theta_{c}^{3 / 2} \sqrt{\frac{6 V_{s} D W}{Q_{w}}} .
$$

Therefore, near threshold, the slope of a fan should be close to critical. This remark prompts us to interpret the geometry of our experimental fans within this framework.

Direct observation reveals that almost no sediment leaves the experiment before the fan extends to the outlet. As the fan consumes more glass beads to grow, the sediment discharge decreases along the channel. Therefore, if we restrict the sediment discharge $Q_{s}$, we restrict the sediment flux downstream and maintain the entire fan at about the critical slope $S_{c}$. Based on this hypothesis, we can relate the volume of the fan to its length:

$$
L \approx \sqrt{\frac{2 Q_{s} t}{(1-\lambda) S_{c} W}} \equiv L_{0} .
$$

where $\lambda$ is the porosity of the settled granular material. In two dimensions, a similar mass balance would lead to a cubic-root time dependance [7].

Indeed, after a transient, the length of our experimental fan grows linearly with the square root of time (figure 5). In addition, equation (5) provides a reasonable estimate of the proportionality constant relating the fan length to the square root of time.

Although reminiscent of the well-known scaling of Fickian diffusion, this length growing as the square root 


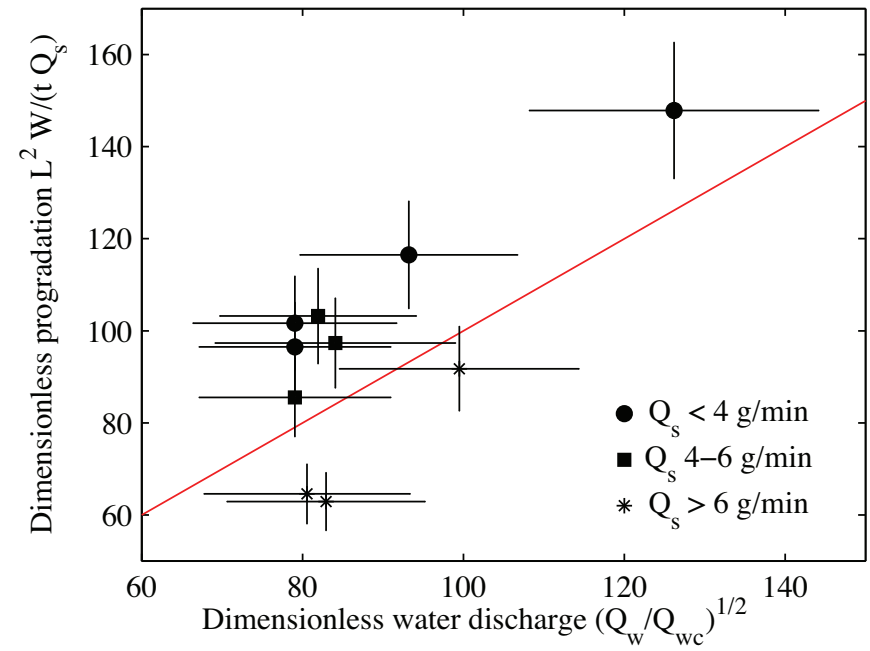

Figure 6. (Color online) Predicted (red (gray) line) and observed (black points) dimensionless progradation according to the dimensionless water flux.

of time results from mass conservation only and is not related to any diffusive process.

Combining relation (4) and (5), we find:

$$
\frac{L_{0}^{2} W}{t Q_{s}}=\sqrt{\frac{Q_{w}}{Q_{w c}}}
$$

where $Q_{w c}$ is a characteristic water discharge:

$$
Q_{w c}=\frac{3}{2} \theta^{3}(1-\lambda)^{2}\left(\frac{\rho_{s}-\rho_{f}}{\rho_{f}}\right)^{2} V_{s} D W
$$

In order to compare more accurately this prediction with our experiments, we vary the discharges of water and sediments and measure the resulting progradation (i.e. the advance of the fan toe). We find that equation (6) provides a reasonable estimate of the growth rate of the fan (figure 6). A combinaison of experimental limitations and the drastic approximations used to derive the theoretical relationship explain the scatter of the data. First, the fluid discharge, the fluid viscosity and the sediment discharge fluctuate slightly during an experimental run (up to 10\%). Due to surface tension, part of the sediments float and leave the experiment without contributing to the fan. In addition, we expect the shallow-water approximation to break down for large fluid discharges.

At this point, we may summarize our findings as follows. When the sediment discharge is moderate, the fan grows quasi-statically. In this regime, the water discharge controls its geometry, since the slope adjusts to the threshold for sediment transport. The sediment discharge determines the growth rate of the fan, but does not influence its shape significantly.

\section{SEDIMENT TRANSPORT ALONG THE FAN}

This section is devoted to the next order of the threshold approximation. It will not alter significantly the conclusions of the previous section, but it should clarify the mechanism by which the sediments are distributed along the fan.

\section{A. Exner equation}

The fan grows from sediment deposition. The sediment mass balance, often referred to as the Exner equation in the context of geomorphology, formalizes this process:

$$
(1-\lambda) \frac{\partial h}{\partial t}+\frac{\partial q_{s}}{\partial x}=0
$$

where $q_{s}$ is the sediment transport rate.

To describe the growth of a fan, the Exner equation must be complemented with the sediment transport law (equation (3)). Based on equation (4), we rewrite the transport law in terms of slope [24]:

$$
q_{s}=\frac{\alpha V_{s} D \theta_{c}}{S_{c}^{2 / 3}}\left[\left(-\frac{\partial h}{\partial x}\right)^{2 / 3}-S_{c}^{2 / 3}\right],
$$

Combining equations (9) and (8) results in a secondorder partial differential equation, which requires two boundary conditions. However, since we cannot specify the length of the fan $L$ a priori, the domain over which we must solve the Exner equation has a free boundary. It is a Stephan problem, which requires an additional boundary condition [25].

We propose three empirical boundary conditions:

- At the inlet, the sediment discharge is set by the experimental conditions: $q_{s}(0, t)=Q_{s} / W$.

- By definition, the fan elevation vanishes at its end: $h(L(t), t)=0$.

- Finally, the fan traps all the sediments. Therefore, at the fan's end, the sediment discharge vanishes: $q_{s}(L(t), t)=0$.

\section{B. Self-affine fan}

Formally, equations (9), (8) and the three boundary conditions could be solved directly, at least numerically. However, it might prove more instructive to look for a simple analytical solution, in the form of a self-affine fan.

Based on section II, we expect the length of a self-affine fan to scale like:

$$
L(t)=\mathcal{L} \sqrt{\frac{2 Q_{s} t}{(1-\lambda) S_{c} W}},
$$


where $\mathcal{L}$ is a dimensionless constant, close to one. We then rescale the fan profile with this length:

$$
h(x, t)=S_{c} L(t) h_{*}\left(\frac{x}{L(t)}\right)
$$

where $h_{*}$ is the self-affine shape of the fan. The critical slope $S_{c}$, defined by equation (4), sets the aspect ratio of the fan.

Similarly, we define a dimensionless sediment discharge $q_{s *}$ as:

$$
q_{s}(x, t)=\frac{Q_{s}}{W} q_{s *}\left(\frac{x}{L(t)}\right) .
$$

Injecting $h_{*}$ and $q_{s *}$ in the Exner equation (8) and the transport law (9), we obtain two ordinary differential equations:

$$
h_{*}-X h_{*}^{\prime}+\frac{q_{s *}^{\prime}}{\mathcal{L}}=0
$$

and

$$
\epsilon q_{s *}=\left(-h_{*}^{\prime}\right)^{2 / 3}-1
$$

where $X=x / L(t)$ is the rescaled coordinate and

$$
\epsilon=Q_{s} /\left(\alpha W V_{s} D \theta_{c}\right)
$$

is the dimensionless sediment discharge. The three boundary conditions become:

$$
q_{s *}(0)=1, \quad q_{s *}(1)=0 \quad \text { and } \quad h_{*}(1)=0 .
$$

That the evolution equations can be re-written in a self-affine form suggests the experimental fan could also be self-affine, even beyond first order. To evaluate this hypothesis, we rescale the successive profiles of an experimental fan with its length (figure 7). By focusing on a single experiment, we insure that the critical slope $S_{c}$ and the dimensionless sediment discharge $\epsilon$ are constant. At long times, the rescaled profiles tend to collapse on a single shape, indicating a self-affine growth. As a consequence, after a transient, the fan slope converges towards a constant value (figure 8). This monotonous convergence contrasts with previous observations from twodimensional laboratory fans [7]. The absence of avulsion in our experiments might explain this difference.

Combining the last five profiles of figure 7 , the resulting self-affine shape shows an unambiguous curvature (figure 9). This curvature must be related to sediment transport, since the strict threshold theory predicts a uniform slope (section II). In what follows, we aim at quantifying this relationship.

\section{Low sediment discharge}

To our knowledge, equations (13), (14) and (16) have no simple analytical solution. We may circumvent this difficulty by considering the quasi-static growth of a fan.

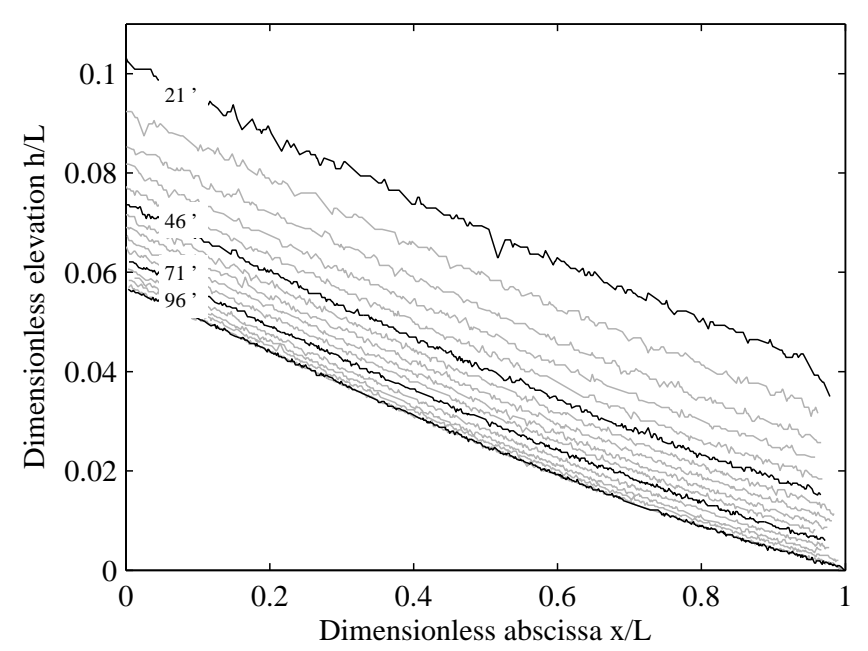

Figure 7. Fan profiles collected at successive stages of the same experimental run $\left(Q_{s}=9.1 \mathrm{~g} \mathrm{~min}^{-1}, Q_{w}=0.54 \mathrm{~L}\right.$ $\min ^{-1}$ ) and rescaled with their own length. Time starts at the beginning of the experiment. Black and grey profiles are separated by $5 \mathrm{~min}$.

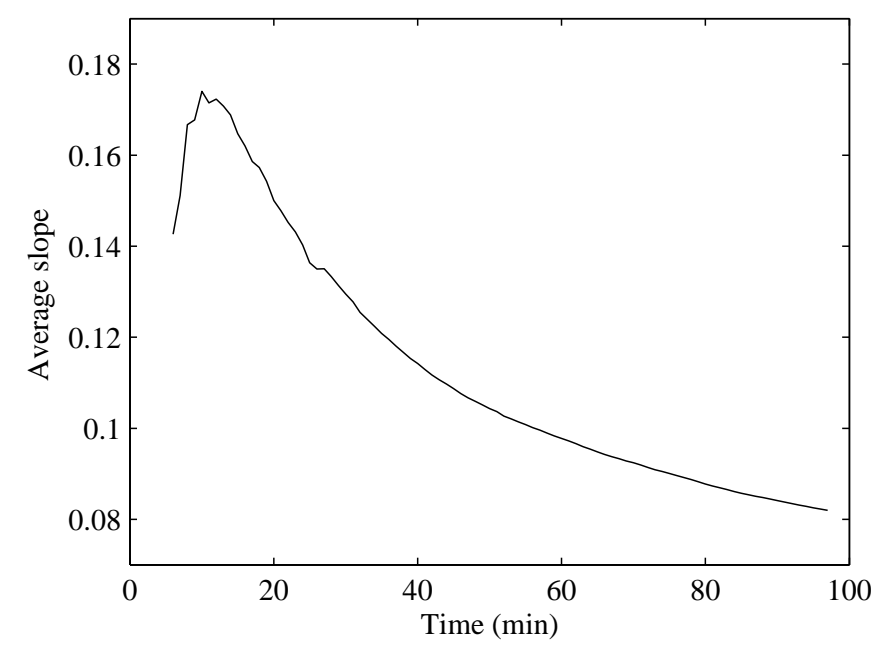

Figure 8. Evolution of the fan slope during the experimental run of figure 7 . The slope is measured by fitting an affine relation to the data.

More specifically, we seek an approximate solution of equations (13), (14) and (16) when the dimensionless sediment discharge $\epsilon$ is small (in our experiments, $\epsilon$ never exceeds 0.8). Accordingly, we expand the solution to first order in $\epsilon$ :

$$
h_{*}=h_{0}+\epsilon h_{1}, \quad q_{s *}=q_{s 0}+\epsilon q_{s 1}, \quad \mathcal{L}=\mathcal{L}_{0}+\epsilon \mathcal{L}_{1} .
$$

Injecting the expanded form of the solution in equations (13), (14) and (16), and expanding the resulting equations to first order, produces two sets of equations corresponding to the zeroth and first orders.

As expected, the zeroth-order solution corresponds to the triangular fan described in section IIB, for which 


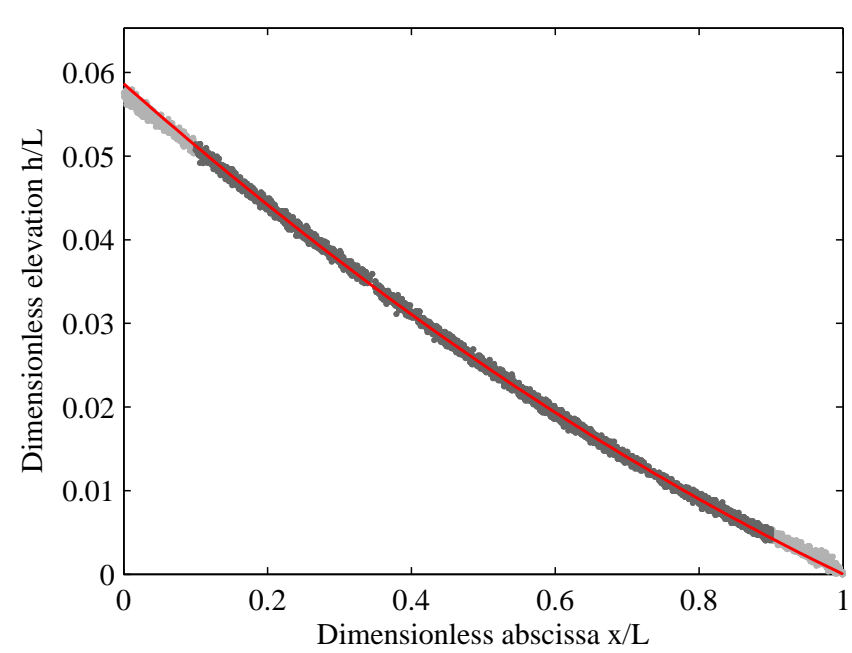

Figure 9. (Color online) The last five profiles of figure 7 (grey dots). The red (gray) line corresponds to equation (20) with coefficients $S_{c}$ and $\epsilon$ fitted to the data. Light grey dots indicate data discarded before fitting.

the sediment inputs is uniformly distributed over the fan surface:

$$
h_{0}=1-X, \quad q_{s 0}=1-X, \quad \mathcal{L}_{0}=1 .
$$

More interestingly, the first-order term take the form of a parabola, thus adding a slight curvature to the triangular fan:

$$
h_{1}=\frac{3}{4}(1-X)^{2}, \quad q_{s 1}=X\left(X^{2}-1\right), \quad \mathcal{L}_{1}=\frac{3}{4} .
$$

At this point, it is perhaps more telling to return to the physical space where the fan profile reads:

$$
\frac{h}{L}=S_{c}\left[1-\frac{x}{L}+\frac{3 \epsilon}{4}\left(1-\frac{x}{L}\right)^{2}\right] .
$$

According to equation (20), sediment transport adds a concave correction to the triangular fan. This shape depends on two parameters only: the critical slope $S_{c}$ (which depends on the water discharge) and the dimensionless sediment discharge $\epsilon$ (which is independent of the water discharge). Remarkably, this double dependence cannot be reduced to the dimensionless ratio of the two discharges only.

We can measure $\epsilon$ by fitting the two coefficients of equation (20) to the rescaled experimental profiles (figure 9). Repeating this procedure for a series of experiments involving various combinations of flow and sediment discharges, we can compare the measured value of $\epsilon$ to its theoretical expression (equation 15). We find an order-of-magnitude agreement between the two, with considerable dispersion of the data (figure 10).

This dispersion exceeds the measurement uncertainty of the profile curvature. In addition to the theoretical

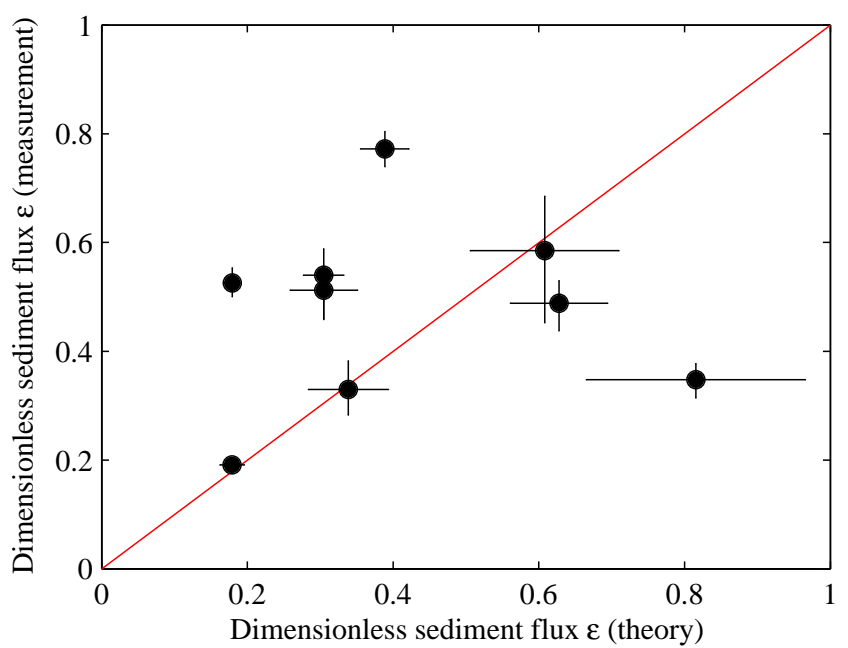

Figure 10. (Color online) Observed dimensionless sediment flux $\epsilon$ according to the expected values for several experiments performed with various water and sediment fluxes.

limitations exposed in section II B, the low sediment discharge approximation might break down in our experiments. Indeed, the dimensionless sediment flux $\epsilon$ is not confined to vanishingly small values (figure 10).

\section{CONCLUSION AND PERSPECTIVES}

A relatively light laboratory set-up produces a onedimensional alluvial fan amenable to simple physical understanding. When the sediment input is restricted, this fan maintains a self-affine shape as it grows.

To leading order, the water discharge sets the geometry of the fan by maintaining its slope near its critical value, in agreement with previous experimental observations [7]. Through mass balance, the sediment discharge determines the velocity the fan grows at. In particular, the fan length increases as the square root of time, a scaling limited to our one-dimensional configuration.

In addition, the careful examination of the fan elevation profile confirms the slight curvature observed in previous experiments [13]. This departure from the threshold theory is a signature of sediment transport, which may be used to infer the sediment input at the fan apex. The morphology of the fan could thus reveal how fast it grows.

None of the above results applies quantitatively to natural systems since real alluvial fans are two-dimensional, rivers are turbulent and sediments are often a mixture of disperse grain sizes. The experimental realization of a two-dimensional fan built by a single-thread stream would be a step in this direction. Removing the two panels which, in the experiment presented here, confine the fan in one dimension would have two major consequences: the river would (i) distribute sediments over a self-formed cone and (ii) spontaneously selects its own 
width and slope. The mass balance can be easily adapted to the uniform distribution of sediments over a cone to describe the average growth of a two-dimensional fan [3]. As for the river slope, the fixed-bank channel used here presents a behavior similar to that of two-dimensional experiments where the slope also reaches a threshold when the sediment discharge vanishes [18].

We hope that some of the ideas developed here might apply to more realistic systems, since previous experiments involving two-dimensional turbulent flows and multiple grain sizes accord qualitatively with our results $[7,13]$. Therefore, we believe that the method proposed here might help us better understand how alluvial fans form in Nature.

\section{ACKNOWLEDGMENTS}

We thank R. Vasquez and H. Bouquerel for their help in building the experimental set-up. This work was funded by the CEFIPRA 4500-W1 grant to F. M.. This paper is IPGP contribution 3553.
[1] W. B. Bull, Geomorphology of segmented alluvial fans in Western Fresno County, California, Tech. Rep. (1964).

[2] S. A. Schumm, The fluvial system (John Wiley \& Sons Inc., 1977) $338 \mathrm{p}$.

[3] G. Parker, Journal of Hydraulic Research 37, 805 (1999).

[4] K. X. Whipple, G. Parker, C. Paola, and D. Mohrig, The Journal of Geology 106, 677 (1998).

[5] M. Van Dijk, G. Postma, and M. G. Kleinhans, Sedimentology 56, 1569 (2009).

[6] L. Clarke, T. A. Quine, and A. Nicholas, Geomorphology 115, 278 (2010).

[7] M. D. Reitz and D. J. Jerolmack, Journal of Geophysical Research: Earth Surface 117 (2012).

[8] J. P. Milana and L. Ruzycki, Journal of Sedimentary Research 69, 553 (1999).

[9] G. Weissmann, G. Bennett, and A. Lansdale, Special Publication - Geological Society of London 251, 169 (2005).

[10] A. Jayko, Earth-Science Reviews 73, 271 (2005).

[11] J. Stock, K. Schmidt, D. Miller, GSA Bulletin 120, 619 (2007).

[12] G. Parker, P. R. Wilcock, C. Paola, W. E. Dietrich, and J. Pitlick, Journal of Geophysical Research: Earth Surface 112 (2007).

[13] C. Paola, G. Parker, R. Seal, S. Dietrich, J. Southard, and P. Wilcock, Science 258 (1992).
[14] R. E. Glover and Q. L. Florey, Stable channel profiles, Tech. Rep. (U.S. Bur. Reclamation,, 1951).

[15] F. M. Henderson, Transactions of the American Society of Civil Engineers 128, 657 (1963).

[16] G. Parker, Journal of Fluid Mechanics 89, 127 (1978).

[17] O. Devauchelle, A. P. Petroff, A. E. Lobkovsky, and D. H. Rothman, Journal of Fluid Mechanics 667, 38 (2011).

[18] G. Seizilles, O. Devauchelle, E. Lajeunesse, and F. Métivier, Physical Review E 87, 052204 (2013).

[19] J.-P. Bouchaud, M. Cates, J. R. Prakash, and S. Edwards, Journal de Physique I 4, 1383 (1994).

[20] G. Parker, C. Paola, K. X. Whipple, and D. Mohrig, Journal of Hydraulic Engineering 124, 985 (1998).

[21] G. Seizilles, E. Lajeunesse, O. Devauchelle, and M. Bak, Physics of Fluidss 26, 013302 (2014).

[22] F. Charru, H. Mouilleron, and O. Eiff, Journal of Fluid Mechanics (2004).

[23] A. E. Lobkovsky, A. V. Orpe, R. Molloy, A. Kudrolli, and D. H. Rothman, Journal of Fluid Mechanics 605, 47 (2008).

[24] L. Malverti, E. Lajeunesse, and F. Métivier, Journal of Geophysical Research: Earth Surface 113 (2008).

[25] J. Swenson, V. Voller, C. Paola, G. Parker, J. Voller, and F. Marr, European Journal of Applied Mathematics 11 (2000) 
Table I. Definitions.

\begin{tabular}{cll}
\hline \hline Notation & Physical quantity & Value \\
$Q_{w}$ & Water discharge & $0.5-1.3 \mathrm{~L} \mathrm{~min}^{-1}$ \\
$Q_{s}$ & Sediment discharge & $0.8-3.6 \mathrm{~cm}^{3} \mathrm{~min}^{-1}$ \\
$q_{w}$ & Water discharge & $3-9.10^{-4} \mathrm{~m}^{2} \mathrm{~s}^{-1}$ \\
$q_{s}$ & Sediment discharge & $0.5-2.10^{-6} \mathrm{~m}^{2} \mathrm{~s}^{-1}$ \\
$Q_{w c}$ & Characteristic water discharge & $10^{-9} \mathrm{~m}^{3} \mathrm{~s}^{-1}$ \\
$W$ & Channel width & $2.5-3.2 \mathrm{~cm}$ \\
$D$ & Bead diameter & $477 \mu \mathrm{m}$ \\
$\rho_{s}$ & Bead density & $2485 \mathrm{~kg} \mathrm{~m}^{-3}$ \\
$\lambda$ & Porosity of the fan & 0.33 \\
$\rho_{f}$ & Fluid density & $1210-1220 \mathrm{~kg} \mathrm{~m}^{-3}$ \\
$\mu$ & Fluid viscosity & $40-60 \mathrm{mPas}^{\mathrm{s}}$ \\
$\tau$ & Shear stress & $2-3 \mathrm{~Pa}$ \\
$\theta$ & Shields parameter & $0.3-0.5$ \\
$\theta_{c}$ & Critical Shields parameter & 0.35 \\
$S$ & Fan slope & $0.02-0.05$ \\
$S_{c}$ & Critical slope & $0.02-0.04$ \\
$V_{s}$ & Stokes settling velocity & $3 \mathrm{~mm} \mathrm{~s}$ \\
$\alpha$ & Proportionality coefficient of the transport law & 4.9 \\
$\epsilon$ & Dimensionless sediment discharge & $0-1$ \\
\hline \hline
\end{tabular}

